\title{
Health Paradigm Shifts in the 20th Century
}

\section{Jose Miguel DeAngulo and Luz Stella Losada ${ }^{b}$}

${ }^{a} \mathrm{MD}, \mathrm{MPH}$, Regional Director for Latin America, MAP International, Bolivia

${ }^{b}$ MHPE, Community Health Specialist, MAP International, Bolivia

\section{Abstract}

The application of systems theory and the study of complexity to medicine and human health allows for a more comprehensive understanding and a more holistic view of what it means to be human. Such application overcomes the limitations of the traditional, fragmented understanding of phenomena and problems based on the mechanistic or Newtonian worldview. It recognizes that phenomena are interrelated, and that individual parts cannot be understood by only focusing on the analysis of their individual qualities. Rather, the individual parts can only be understood in relation to the whole and by being analyzed in the context of their interaction with the whole. The door is opened to previously unimagined models of thinking.

In the $20^{\text {th }}$ Century there have been shifts in the paradigms that have governed medicine and human health in the modern western world. There has been a shift from the focus on specific biological analysis and pathological diagnostics to complex human interactions with the environment and with sociopolitical and economic processes. There are complex models of systems in immunology, in neuroscience, and in genetics, as well as complex ways of understanding interactions as in epidemic modeling, in social media technologies, socioeconomic factors, and artificial intelligence.

In this paper we describe three paradigms of the health-disease process that in some degree correspond to the historical development of modern medicine and healthcare over the previous century. The oldest paradigm focused on specific disease mechanisms and treatment. This gave way to paradigms that historically were broader and more inclusive, such as "international health". The international health paradigm focused primarily on the control of epidemics across national borders and considered government as the only health actor. However, this perspective has come to be seen as excessively reductionist and excluded many critical components essential to a robust understanding. The old "international health" has in turn been replaced by the paradigm of "global health" that exercises more comprehensive claims, and paved the way for emerging paradigms of complexity in the $21^{\text {st }}$ Century.

\section{Introduction}

We are witnessing the emergence of new paradigms that allow for a more comprehensive understanding of the world in general and various phenomena specifically. These emerging paradigms overcome the limitations of the traditional, fragmented understanding of phenomena and problems based on the mechanistic or Newtonian worldview.
Systems theory and the study of complexity allow for a more holistic view of what it means to be human. ${ }^{1,2}$ These new approaches recognize that phenomena are interrelated, and that individual parts cannot be understood by only focusing on the analysis of their individual qualities. Rather, the individual parts can only be understood in relation to the whole and by being analyzed in the context of 
their interaction with the whole. Complex systems open the door to previously unimagined models of thinking. ${ }^{3}$

Paradigmatic shifts have affected medicine and an understanding of human health in the modern western world. There has been a shift from focus on specific biological analysis and pathological diagnostics to complex human interactions with the environment and with sociopolitical and economic processes. There are complex models of systems in immunology, neuroscience, and genetics, as well as complex ways of understanding interactions as in epidemic modeling, social media technologies, socioeconomic factors, and artificial intelligence. Paradigms that historically were broader and more inclusive, such as "international health" excluded many critical components essential to a robust understanding. The previous "international health" paradigm has been replaced by the paradigm of "global health" that exercises more comprehensive claims. ${ }^{4}$ The international health paradigm focused primarily on the control of epidemics across national borders and considered government as the only health actor; this has come to be seen as excessively reductionist.

In the following paper, we initially discuss two paradigms that share a focus on pathologies and the organism of the individual. Then, we will describe a paradigm shift toward an understanding that the health-disease process is not merely a biological and organic phenomenon in individuals, but represents an attempt to overcome a fragmented focus and attempts to handle reality in a more comprehensive manner. These paradigm shifts in some degree correspond to the historical development of modern medicine and healthcare over the previous century.

\section{Hospital-based Pathogenic Biomedical Paradigm}

This paradigm uses the concept of "pathogenic" because it is based on a search for and discovery of the origin of a disease. Health is viewed as the absence of disease, with disease being defined as a deviation from the normal biological functioning of the body. The paradigm is called "biomedical" because it requires highly qualified scientific personnel, with the doctor playing the main role supported by a team of other professionals such as laboratory technicians, pharmacologists, biochemists, nutritionists, nurses, etc. The human body is viewed as a complex biological machine, requiring the services of "biological engineers" who understand its complex chemical reactions as well as the possible modifications in its cells and organs. The model is called "hospital-based" because health care is delivered primarily in this setting. Biomedicine emphasizes the scientific treatment of the individual. Such services require sophisticated and expensive instruments and high technology equipment. Hospitals, by keeping patients together, can more efficiently utilize both human and technological resources.

This paradigm has many strengths, such as more effective methods for diagnosing and treating life-threatening and disabling diseases. It has saved many lives, alleviated pain, and facilitated the recuperation of patients. It also has several limitations such as high costs for qualified human resources, advanced technology, and extensive infrastructure. It has low geographical, financial, and cultural accessibility. Its high cost affects healthcare everywhere. Low cultural accessibility occurs because of language and worldview differences between patients and service providers affecting how signs, symptoms, and feelings are framed. Misuse of pharmaceuticals constitutes an additional problem. _Furthermore, many doctors and hospitals fail to treat the poor as well as they would treat the wealthy, so that a large sector of the population avoids doctors and hospitals due to the fear of inferior care.

An important limitation of this paradigm has been in the management of disease processes that require intervention in social groups rather than individuals. Even in developed countries, health officials now recognize that a high percentage of pathologies depend on lifestyles that lead to chronic and degenerative diseases. Adoption of a lifestyle has a major social dimension. Linear causality, a feature of the pathogenic aspect of the paradigm, may be insufficient to explain diseases whose cause and evolution is multifactorial. An example of this is the failure to deal with mental illness. A reductionist approach to health care is blamed for making medical practice impersonal and seeing patients as isolated "problems." In the developing world, this limitation of the paradigm may be amplified since the prevalent diseases need to be viewed in the context of complex social, economic, sanitary, environmental, and political conditions.

Infant diarrhea illustrates this. The paradigm says that diarrhea is the result of a virus or parasite being transported by a vector, which in this case is contaminated food or water, to a host, the child. The "colonization" of these germs in the child produces the disease. If the many other factors associated with this illness such as lack of potable water, poor sanitary conditions in which the child 
lives, or lack of time for the mother to care for him due to her excessive work responsibilities are dismissed, this solution begins to be simplistic. The same mother returns a month later with the same child with the same symptoms. The same diagnosis is given as before, and she leaves with the same recommended treatment. This mother will return several weeks later with the same problem. Because of this, hospitals, clinics, and health centers have been called disease palaces or patient recycling centers. This critique has been made by Helfdan Mahler, director general of the World Health organization and Ivan Illich. Mahler has deplored the tendency to devote increasingly large sums of money to maintaining "disease palaces."

Perhaps the best summary critique of this paradigm is that of John Germov:

While the biomedical model represented a significant advance in understanding disease and resulted in beneficial treatments, it has come under significant criticism from both within medicine and from a range of social and behavioral disciplines such as sociology and psychology. The major criticism is that the biomedical model underestimates the complexity of health and illness, particularly by neglecting social and psychological factors ${ }^{6}$

\section{Community-based Bio-Sanitary Pathogenic Paradigm}

In the 1970s, a second paradigm appeared that made efforts go beyond the dominant role of institutions and physicians in managing healthcare. The International Conference of Alma Ata defined primary health care (PHC), as:

... essential health care based on practical, scientifically sound and socially acceptable methods and technology, made universally accessible to individuals and families in the community. It is through their full participation and at a cost that the community and the country can afford to maintain at every stage of their development in the spirit of self-reliance and self-determination. ${ }^{7}$

Although this second paradigm, which we have called the "community-based bio-sanitary pathogenic paradigm", shares many principles with the first one, it has produced advancements in how govern- ment and communities get involved with health care.

Despite the fact that populations, in general, frequently prefer the services provided by the first paradigm, governments and international organizations began promoting Primary Health Care. Instead of concentrating on the human body and disease, the Community-based Bio-sanitary Pathogenic Paradigm takes more account of the role of vectors and the environment in disease. Its emphasis is not on curing diseases as much as in preventing them. This paradigm also shares its predecessor's limitation of proposing that disease originates in biological causes, even though it places more emphasis on the roles played by vectors and microorganisms. For this reason, this paradigm is also given the descriptor "pathogenic". While the disease process is still understood on the basis of the "origin of disease", this paradigm considers that health can be achieved insofar as the community learns to take certain measures to prevent disease and, if disease occurs, learns how to cure it. The paradigm is called "biological" rather than "biomedical" because the physician's role is secondary. Interventions are carried out by personnel with limited training, such as nurses' aides or health promoters. Due to the short training period, the cost of preparing personnel is much lower than for the biomedical paradigm, resulting in more adequate coverage of the population. ${ }^{8}$

A good example of the impact of this paradigm shift was seen in the work done by the nongovernmental organization MAP International. In the 1950s, MAP's work focused on the provision of medicines to hospitals in the developing world. Later in the 70s, 80s and 90s, MAP employed a new strategy that increased involvement with local communities and explored causes of diseases and what could be done to prevent them. The international shift to this new paradigm was published by MAP in New Agenda for Medical Missions, edited by D. Merrill Ewert. ${ }^{9}$ The book contains a variety of reflections about the contribution to international health provided by the thinking and experiences of medical missionaries working in developing countries. This second health paradigm opened the door for lay people to play a key role in the health of their communities, even those with minimal formal education.

Even though the Alma Ata movement offered greater coverage of health services, several groups and governmental authorities began to call the movement unrealistic and unattainable. To respond to this criticism, Selective Primary Health Care 
(SPHC) was launched. This offered low-cost interventions to address the most prevalent diseases: oral rehydration for diarrheal diseases, breastfeeding and monitoring to fight malnutrition, malaria treatment, and immunizations. There were efforts to produce a set of technical, linear, and fragmented interventions and programs that could be easily implemented and measured. However, pressure to develop greater reliance on private-sector healthcare provision and the influence of the World Bank to reduce existing inefficient and ineffective health systems led to a reduction of public involvement in broader public health actions.

The new paradigm called for collaboration between health sectors, equity, affordability, and a multidimensional approach to health and socioeconomic development. It emphasized the use of "appropriate technology", and encouraged active community participation in health care and health prevention. This meant that health strategies and activities were carried out in the communities themselves, a contrast with the first paradigm, which was hospital based. Since the CommunityBased Bio-sanitary Pathogenic Paradigm considers health a right of the entire population, it requires the active participation of the entire society in identifying and solving its health problems. Also, it requires access to health services for a population at sites where people live and work. Primary Health Care came to embody the entire collection of health intervention strategies featured by this paradigm.

In 1982/83, the United Nations Children's Fund (UNICEF) established A Revolution for the Children. This featured growth monitoring, breastfeeding, immunizations, management of diarrhea, and family planning. The main argument for this strategy has been that it only costs a few dollars per child. The success of the World Health Organization's (WHO) Intensified Smallpox Eradication Program appeared to justify other such targeted programs. There was an expectation that future vaccines against diseases such as malaria, rotavirus, leprosy, and AIDS, among others, would lead to the success of "Health for All by the Year 2000." More recently, social marketing has been used to encourage people towards specific behaviors in the targeted conditions.

This paradigm is less reductionist than the first and provides broader coverage for targeted health services. People are not assumed to be passive; there are responsibilities that people need to assume in order to be healthy. Accordingly this paradigm puts considerable responsibility on the shoulders of individuals, particularly women. Responsibilities that are rightly those of the government, the community, and the couple in charge of each family have been allocated uniquely to the mother. Such a heavy load may have the effect described by Ashton and Seymour in The New Public Health Movement and illustrated by a well-known parable. The parable describes a health worker diagnosing the same diseases in the same children without looking at the context in which these children live. This is likened to a lifesaver on the bank of a river:

Every so often a drowning person is swept alongside. The lifesaver dives in to the rescue, retrieves the 'patient' and resuscitates them. Just as they have finished another casualty appears alongside. So busy and involved are the lifesavers in all of this rescue work that they have no time to walk upstream and see why it is that so many people are falling into the river. ${ }^{10}$

These two previous paradigms were challenged because of their organicist approach. The health of the society was more than just biological interaction of the human organism with other organisms. Community-based health development should not be managed as isolated biological or sanitary conditions, but should focus on comprehensiveness and the processes generated by the interactions of multiple actors. Even though science has been able to identify the specific biological causes of many diseases and the specific medical actions that need to be taken to cure those diseases, the multiple social, cultural, political, religious, and economic factors that underlie disease processes cannot be managed in isolation. ${ }^{11}$ The traditional western development approach is a problem-driven process. The approach is an expression of Newtonian science that views the world like a gigantic clock with reality made up of discrete parts, each with its individual structure and function. It breaks systems and units into their constituent sub-units and analyzes their distinct elements. A problem-solving approach focuses on "rational dimensions" and, frequently, loses its connection with people's lives and runs the risk of being unnatural and ineffective. A problem-driven development approach reproduces the old model in which the focus is the problem itself instead of the capacity of people to build healthy and sustainable environments, to maintain healthy behaviors, and to promote policies that foster those environments and behaviors. Problemdriven development takes the effort away from

May 2015. Christian Journal for Global Health 2(1): 49-58. 
building people's capacity for self-agency in their lives.

The Newtonian worldview is inadequate to account for the intricacies and interconnections of complex living and social systems. Problems manifest the failures of social systems to provide self-regulating capabilities that foster the fullness of life. The exploration of more comprehensive approaches to development that deal with a holistic model of reality is urgent. Understanding community reality implies recognizing local people's capacity to be aware of the interconnections, mutual influences, and dynamic relationships that flow among the elements of their community and history. When a learning and development approach is embedded in the day-to-day context of the people, its impact is more natural, effective, and sustainable. Models of intervention need to be selforganizing, dynamic, and complex enough to deal with the wholeness of reality.

\section{Health-genic Systemic Ecological Para- digm of Comprehensive Health}

The effort to construct a more comprehensive understanding of health produced the emergence of what we call the "Health-genic Systemic Ecological Paradigm." We employ the descriptor "health genic" to indicate that it is not pathogenic. In other words, the Health-Disease process is not understood on the basis of the origin of disease, but on the origin of health, the way to achieve a full and abundant life. It recognizes and defends, at personal, family, community, and societal levels, the role of the different elements of the bio-psycho-social life of the human being. Each element represents an ecosystem in which life is experienced. The paradigm requires individuals, families, and communities to live in a mutually binding and integrated way, making choices for life instead of choices which promote death. The choice for life is people committing themselves to transform the world in ways that establish a society marked by justice, liberty, and harmony.

The role states and societies need to play in health determinants has been a force for the emergence of this third paradigm. The International Conference on Health Promotion held in Ottawa in 1986 presented the charter for action to achieve Health for All by the year 2000 and beyond. ${ }^{12}$ In the 1990s, the World Health Organization published Social Determinants of Health: The Solid Facts. ${ }^{13}$ This stated that actions for health need to be geared towards addressing the social determinants of health in order to attack the causes of ill health before they can lead to problems. It showed the strength of the scientific evidence on social determinants and presented them in a clear and understandable form. A broad classification to deal with social factors was presented in a newer version of this document showing a remarkable sensitivity of health to the social environment. A list of ten critical topics that need to be addressed for healthy societies included the following: the social gradient, stress, early life, social exclusion, work, unemployment, social support, addiction, food, and transport. ${ }^{14}$ This list went beyond the biomedical and bio-sanitary paradigms and put social systems in the center of the analysis.

Complex thinking helps us to deal more effectively with complex realities. ${ }^{16}$ In the effort of constructing a more comprehensive understanding of reality, Edgar Morin invites us to go beyond simplicity and to engage complexity. ${ }^{15}$ This may allow us to develop a way of thinking, being, and acting that in its wholeness is without fragmentation or mutilation of life. This is in contrast to adherence to only one perspective provided by only one discipline and controlled by the hyper-specialization continually promoted in the academic world. Complex thinking may facilitate people to become richer in feeling and intuition and to live more fully with ourselves and with others by being more sensible of and appreciative of the complexities, paradoxes, tragedies, joys, failures, fears, dreams, and successes that occur every day. Complex thinking helps people become trans-disciplinary in their thinking, more creative, more strategic, and more oriented toward the search for new possibilities. Even though this approach to health is hampered by the privatization of health-care services and the division of "purchaser" and "provider" functions, it is critical that all sectors of society be organized to maintain a comprehensive approach. Those who consider themselves as Jesus's followers and have opportunity to understand the concepts of shalom (peace, completeness, wholeness, welfare), sozo (to save, keep safe and sound, to rescue from danger or destruction) and zoteria (salvation deliverance) cannot turn their back to the core message of Jesus. Fragmented attention to particular aspects of health easily diverts attention from the determinants of health and discourages cooperation between different sectors of society. As Robert Beaglehole and Ruth Bonita state, a public health approach that incorporates a multidisciplinary and intersectorial approach to the health determinants is the way forward in order for society to achieve wellbeing for all: 
A broad focus easily leads to accusations of "woolly breadth", but this breadth is exactly for public-health practitioners is to justify and promote global concerns and at the same time what public health should be about. The challenge proceed with evidence-based, public-health inequalities. ${ }^{16}$

The human rights movement in the second part of the twentieth century showed a link between the exercise of human rights and people's health and wellbeing. This linkage indicated the need for a spectrum of strategies and activities that went beyond traditional primary health care services. Public health practitioners and organizations committed to the Health for All movement began to explore the best avenues to build healthy societies. The Ottawa Charter for Health Promotion sets out the following framework:

- Build public policies which support health.

- Create supportive environments.

- Strengthen community action.

- Develop personal skills.

- Re-orient health services. ${ }^{13}$

Paradigms that see and describe the world using words like organic, holistic, and ecological have been promoted by new developments in physics and related sciences. The universe is no longer seen as a machine, made up of separate objects, but as one indivisible, dynamic whole whose parts are interrelated. The mechanistic, hierarchical cause-effect understanding of the universe has been replaced by a world of multiple and complex processes and interactions. Parts interact and influence each other, acting as partners; compartmentalizing or fragmenting this integrated reality risks harming the whole. As the health of one individual cannot be understood as the sum of the health of each part or organ, neither can the individual be considered apart from his/her relationships and interactions with the community and the environment. New ways of understanding these interactions are required to be able to care for and embrace the whole person. Instead of focusing on diseases and biological processes, a broader scientific approach is needed to identify health determinants and how governments and civil society need to learn how to monitor, and care for those health determinants.

Even though this third paradigm became consolidated in the last decade of the 20th century, the initial foundation was laid down many years before, even during the 19th century; Rudolf Virchow, then, and Salvador Allende, more recently, were clear examples, acknowledging the social origins of illness; showing how workplace and environment cause infection, disease and disability; and promoting a new view of social etiology and multi-factorial causation. Social epidemiology identified social patterns of health and illness - such as the different health status between women and men, between the poor and the wealthy, or between the indigenous and non-indigenous populations. This helped reveal social rather than the traditional biological explanations. New voices began to affirm that the primary determinants of disease are mainly economic and social; therefore, its remedies must also be economic and social. ${ }^{17}$

A number of epidemiological studies show the role income, shelter, education, access to nutritious food, services, community norms and cohesion, and social justice play in the health of communities and individuals. Social determinants affect the factors and resources essential to the health of communities and individuals as well as the resources available to support their health and to deal effectively with illness and disease. Social determinants cluster around three basic areas: income inequality, social connectedness, and sense of personal or collective control over one's life or self-efficacy. This understanding has led to a movement to develop policies and strategies to promote social equity in health. ${ }^{18}$

Health needs to be understood by merging key ideas from ecology, medicine, genetics, immunology, and epidemiology. ${ }^{19,20,21}$ There is an acknowledgment of the role a stable ecosystem plays in the health of society. Clean air, clean water, and protection of the natural environment are critical components of achieving health. This includes sustainable resources such as water, farmland, minerals, industrial resources, plants, animals, and renewable sources of power such as sun, wind, water, and biomass, etc. ${ }^{22}$ An ecological view of health allows what we call a "health-genic" understanding about the health and disease process. In this health-genic model, comprehensive health is understood as a social process which enables individuals and societies to adapt dynamically to their environment. It also enables individuals and societies to avoid progressive conflict or disease and conditions whose presence poses a high risk of damaging their state of health. Comprehensive health is the capacity for full self-actualization according to the will of God in its various bio-psycho-social aspects in a self-sustaining manner that does not jeopardize the conditions which would allow successive genera- 
tions to experience this fullness. This is why it is necessary to be sensitive to the interactions and processes between the different actors or social groups and the systems that regulate how they live and interact. The processes, themselves, modify human systems that in turn generate social forces for change and transformation.

Comprehensive Health must seek to promote a new way of appreciating human beings and life through modifications of the interaction between different social systems or subsystems. Now large sectors of population cannot remain passive, waiting for governments to do something to remove a disease or a group of health problems. Multiple organized groups see that systems need to be effective if they want to overcome these problems; they want to put pressure on government to become more effective. As the article Reinventing public health: A New Perspective on the Health of Canadians and its international impact states:

In the 1970s all the English-speaking developed nations were facing deficits as curative costs rose. Adopting health promotion policies permitted them to shift responsibility back to local governments and individuals while limiting their expenditures. Health and community activists, however, used this concept to broaden their focus to include the social, economic and political determinants of health and thus reinvented public health discourse and practice for the 21 st century. ${ }^{23}$

Social systems modify historical processes in different areas of human life including health. If we seek long-term changes, it is useful to observe, evaluate, and analyze the processes generated by these systems. The environment, both natural and modified, and individual and collective behaviors are the largest determinants of health conditions in a community. Acquiring information and skills is not sufficient to generate changes with regard to health; it also requires developing personal and community power to implement changes.

\section{Total Health Example}

An example of how to use a systems and health-genic approach is the effort that MAP International expressed in the strategy for Total Health summarized in an unpublished internal document elaborated by the president Michael Nyenhuis in $2007 .^{24} \mathrm{He}$ offered a definition of Total Health not as describing the state of someone's health, as if he or she is free from illness, disease or other conditions. Rather, Total Health describes the ways that individuals, families, and communities can take responsible action to improve their well-being. It is the integration of two important ideas:

\section{Self-empowerment}

Transformation and sustainable change happen when individuals, families, and communities discover and begin to exercise the God-given power they have over their own lives. They are responsible to "create their own momentum, gain their own skills, and advocate for their own change," as the World Health Organization wrote in a paper, "What is the evidence on effectiveness of empowerment to improve health?"25 Approaches grounded in Total Health must help communities discover their power and build their own capacity to improve their wellbeing. Research increasingly shows that health outcomes are dependent on self-empowered citizens actively participating in their own change. If outside experts always plan and implement health interventions - even comprehensive ones communities will be disempowered and without incentive to solve their own future problems.

\section{Holism}

A holistic or comprehensive view of health recognizes the inter-connected spiritual, physical, emotional, social, and other factors that influence wellbeing. MAP's broad understanding of health comes from scripture, from the Hebrew word shalom. Sometimes translated "health," shalom actually implies a much broader conception of wholeness, wellbeing, and peace in every area of life. Truly effective, transformational projects must work toward this ideal. This is why, for instance, we resist simple interventions so common in development work. A typical "child survival" project might have as its goal adding vitamin A and zinc to the diets of children. While important, these simple interventions do not address the integrated factors that influence the health and wellbeing of children. Our desire is to address - as well as we can and in partnership with others - the whole, rather than individual parts.

With that in mind, Total Health is defined as communities taking ongoing, comprehensive action to improve their health and wellbeing.

MAP Bolivia's work done through Chilimarca programs is a good model of transformational work in the area of Total Health, showing how individuals, organizations, families, and communities can experience an "inside-out" process, a self-

May 2015. Christian Journal for Global Health 2(1): 49-58. 
empowerment journey to heal brokenness in their lives and progressively gain control over health determinants. Individuals, families, communities, and organizations have progressively developed a better understanding of how to pursue the fullness of physical, spiritual, relational, and mental wellbeing of God's shalom. This model has shown how efforts toward Total Health communities or nations require far more than the work of medical professionals. Gaining control over the personal and social determinants of health requires family and community programs that engage people in the process of transforming their lives and learning to live in harmony with each other, with God, and with nature. These elements all provide resources for healthy living and what will allow them to experience abundant and meaningful life in a sustainable way without jeopardizing the life of coming generations. Large changes have been experienced by MAP staff in Bolivia, their families, the organization, and the communities with which they have been working. Political advocacy efforts on violence against children and on human rights violations increase the holistic perspective. They indicate the large impact MAP can have in other countries in Latin America and the world. ${ }^{26,27}$

The engagement of Christian organizations with communities to go beyond the traditional approach of treating and preventing diseases, lowering exposure to germs, and to seek the transformation of social health determinants has helped to show that God really cares for the suffering and injustice experienced by large sectors of society. If the announcement of "a God disconnected from the world" led to a society that attempted to live in "a world without God," committed Jesus-followers engaged in the transformation of society will allow people to see that God comes to their midst seeing the signs of the abundant life Jesus has offered. If the primary determinants of many diseases are mainly economic and social, a true engagement with the health of a society must also include economic and social engagement. In the same way that medicine, politics, and social transformation should not be kept apart ${ }^{28}$, the spirituality and faith of Jesus' followers must be clearly integrated in their faith and practices as health professionals contributing to the transformation of the world.

\section{Foundations for the Future}

The end of the 20th Century left us with an open horizon to address the root causes of many health problems and also the health determinants fostering familial, communal, and societal wellbe- ing. At the turn of the century, neuroscience research provided the material for developing a new understanding of how people think, learn, and behave. Though this research was not then considered critical for addressing global health, it has provided the foundations for a new health paradigm. This would focus on the critical period of life during which human beings establish their brain architecture and lay the foundations of the key determinants for mental and physical health.

The last verse of the Old Testament's last book calls fathers to turn their hearts to the children.

Behold, I will send you Elijah the prophet before the coming of the great and dreadful day of the LORD: And he shall turn the hearts of the fathers to the children, and the hearts of the children to their fathers, lest I come and smite the earth with a curse. (Malachi 4:5.6)

A new $21^{\text {st }}$ Century paradigm would call all of humanity to turn their hearts toward the children, to go to the children to understand critical aspects about how we can become a healthier society. It is as if God were using science to announce - as the Prophet Elijah and John the Baptist did in former times - that the time has arrived for the turning of our hearts toward the children.

And he shall go before him in the spirit and power of Elijah, to turn the hearts of the fathers to the children, and the disobedient to the wisdom of the just; to make ready a people prepared for the Lord. (Luke 1:17)

Jesus invites us to a precious encounter with Him by turning our hearts toward and receiving children into our lives: "Whoever receives one little child like this in My name receives Me." (Mat 18:5)

\section{References}

1. Morin E. From the concept of system to the paradigm of complexity. J Soc Evol Syst. 1992;15(4):37185. http://dx.doi.org/10.1016/1061-7361(92)90024-8

2. Morin E. On complexity (advances in systems theory, complexity, and the human sciences). Cresskill, NJ: Hampton Press; 2008.

3. Samet RH. Exploring the future with complexity science: the emerging models. Fut Evol Psych.

May 2015. Christian Journal for Global Health 2(1): 49-58. 
2011;43(8):831-9.

http://dx.doi.org/10.1016/j.futures.2011.05.025

4. Brown TM, Cueto M, Fee, E. The World Health Organization and the transition from "international" to "global" public health. Am J Public Health. 2006 Jan;96(1):62-72.

http://dx.doi.org/10.2105/AJPH.2004.050831

5. Last JM, Wallace RB, editors. Maxcy-Rosenau-Last Public health and preventive medicine 11th ed. Norwalk, Connecticut: Appleton \& Lange; 1980. [p. 1709]

6. Germov J. Second opinion: an introduction to health sociology. Melbourne, Australia: Oxford University Press; 2009. [p.12]

7. World Health Organization. Declaration of AlmaAta. Adopted at the International Conference on Primary Health Care; 1978 Sept 12; Alma-Ata, USSR.

8. Perry HB, Zulliger R, Rogers MM. Community health workers in low-, middle-, and high-income countries: an overview of their history, recent evolution, and current effectiveness. Annu Rev Publ Health. 2014 Mar;35:399-421.

http://dx.doi.org/10.1146/annurev-publhealth-032013$\underline{182354}$

9. Ewert DM, editor. New agenda for medical missions. Brunswick, GA: MAP International; 1990.

10. Ashton J, Seymour H. The new public health: the Liverpool experience. Open University Press; 1988. [p. vii]

11. Mustard F, Frank J. The determinants of health. CIAR Publication No. 5. Toronto: Canadian Institute of Advanced Research; 1991.

12. World Health Organization. The Ottawa Charter for health promotion. Adopted at the International Conference on Health Promotion; 1986 November 21;

Ottowa, Canada: WHO. Available from:

http://www.who.int/healthpromotion/conferences/previ ous/ottawa/en/

13. World Health Organization. Social determinants of health: the solid facts. Copenhagen, Denmark: WHO; 1998. Available from:

http://www.euro.who.int/_data/assets/pdf_file/0005/9 8438/e81384.pdf

14. World Health Organization. Social determinants of health: the solid facts. $2^{\text {nd }}$ ed. Marmot M, Wilkinson R, editors; Copenhagen, Denmark: WHO; 2003. Available from:

http://www.euro.who.int/en/publications/abstracts/socia 1-determinants-of-health.-the-solid-facts
15. Morin E. From the concept of system to the paradigm of complexity. J Soc Evol Syst. 1992;15(4):37185. http://dx.doi.org/10.1016/1061-7361(92)90024-8

16. Beaglehole R., Bonita R. Public health at the crossroads: which way forward? Lancet. 1998;351:590-2. [p. 591] http://dx.doi.org/10.1016/S0140-6736(97)09494-4

17. Waitzkin H, Rosen G. The evolution of social medicine. In: Freeman HE, Levine S, Reeder LG, editors. Handbook of medical sociology. Englewood Cliffs NJ: Prentice Hall; 1972. p.30-60.

18. Dahlgren G, Whitehead M. Policies and strategies to promote social equity in health. Stockholm, Sweden: Institute of Futures Studies; 1991.

19. Gesler WM., Bird ST, Oljeski SA. Disease ecology and a reformist alternative: the case of infant mortality. Soc Sci Med. 1997;44(5): 657-71.

http://dx.doi.org/10.1016/S0277-9536(96)00219-5

20. Real LA. Sustainability and the ecology of infectious disease: diseases and their pathogenic agents must be viewed as important parts of any ecosystem management strategy. BioScience. 1996;46(2),88-97. http://dx.doi.org/10.2307/1312811

21. Collinge SK, Ray C. Disease ecology: community structure and pathogen dynamics. Cary, North Carolina: Oxford University Press; 2006.

22. KU Work Group for Community Health and Development. The community tool box, section 3 . Healthy cities/healthy communities. [Internet] Lawrence, KS: University of Kansas; 2010. Available from: http://ctb.ku.edu/en/table-of-contents/overview/modelsfor-community-health-and-development/healthy-citieshealthy-communities/main

23. MacDougall H. Reinventing public health: a new perspective on the health of Canadians and its international impact. J Epidemiol Commun H. 2007;61:955-9. http://dx.doi.org/10.1136/jech.2006.046912

24. Nyenhuis M. Strategic planning for unpublished internal document. MAP International. 2007.

25. World Health Organization [Internet]. What is the evidence on effectiveness of empowerment to improve health?. Geneva: WHO;2006. Available from: http://www.euro.who.int/en/data-andevidence/evidence-informed-policymaking/publications/pre2009/what-is-the-evidence-oneffectiveness-of-empowerment-to-improve-health

26. Kinman E. Whose clinic is it anyway? A case study of health care access in Bolivia. In Scholarship for 
teaching: case studies in Latin American geography. 2004.

27. Miranda MG. Advocacy, defensa de causas justas y autoempoderamiento. Systematization of MAP's work in Bolivia. 2008.
28. Rose GA. The strategy of preventive medicine. Oxford: Oxford University Press; 1992.

Peer-Reviewed

Competing Interests: None declared.

Correspondence: Jose Miguel DeAngulo, MAP International, Bolivia, mapbol@verizon.net

Cite this article as: DeAngulo JM, Losada LS. Health paradigm shifts in the $20^{\text {th }}$ Century. Christian Journal for Global Health (May 2014), 2(1): 49-58.

(C) DeAngulo JM, Losada LS. This is an open-access article distributed under the terms of the Creative Commons Attribution License, which permits unrestricted use, distribution, and reproduction in any medium, provided the original author and source are properly cited. To view a copy of the license, visit http://creativecommons.org/licenses/by/3.0/

WWW.cjgh.org

May 2015. Christian Journal for Global Health 2(1): 49-58. 